\begin{tabular}{|c|c|}
\hline $\begin{array}{l}\text { Chemistry of } \\
\text { Metals and Alloys }\end{array}$ & $\begin{array}{l}\text { Chem. Met. Alloys } 13 \text { (2020) } 14-22 \\
\text { Ivan Franko National Iniversit of Lviv } \\
\text { wwww.chemetalajournal.org }\end{array}$ \\
\hline
\end{tabular}

\title{
Reciprocal $\mathrm{K}_{2} \mathrm{TeI}_{6}+\mathbf{R b}_{2} \mathrm{TeBr}_{6} \leftrightarrow \mathrm{K}_{2} \mathrm{TeBr}_{6}+\mathbf{R b}_{2} \mathrm{TeI}_{6}$ system: phase relations, crystal and electronic structures
}

\author{
I. BARCHIY ${ }^{1}$, O. ZUBAKA ${ }^{1}$, E. PERESH ${ }^{1}$, V. SIDEY ${ }^{1}$, O. KOKHAN ${ }^{1}$, I. STERCHO ${ }^{1}$, A. FEDORCHUK ${ }^{2,3}$, \\ M. PIASECKI ${ }^{4}$ \\ ${ }^{1}$ Department of Chemistry, Uzhgorod National University, Pidgirna St. 46, 88000 Uzhgorod, Ukraine \\ ${ }^{2}$ Department of Inorganic and Organic Chemistry, Lviv National University of Veterinary Medicine and \\ Biotechnologies, Pekarska St. 50, 79010 Lviv, Ukraine \\ ${ }^{3}$ Department of Physical Chemistry of Fossil Fuels, Institute of Physical-Organic Chemistry and \\ Coal Chemistry named after L.M. Lytvynenko, National Academy of Sciences of Ukraine, \\ Naukova St. 3a, 79060 Lviv, Ukraine \\ ${ }^{4}$ Institute of Chemistry, Environment Protection and Biotechnology, Jan Dlugosz University, \\ Armii Krajowej St. 13/15, 42200 Częstochowa, Poland \\ * Corresponding author.E-mail: igor.barchiy@uzhnu.edu.ua
}

Received May 25, 2020; accepted July 3, 2020; available on-line November 1, 2020

https://doi.org/10.30970/cma13.0400

The stability of the $\mathrm{K}_{2} \operatorname{TeBr}_{6}\left(I_{6}\right)$ and $\operatorname{Rb}_{2} \operatorname{TeBr}_{6}\left(I_{6}\right)$ compounds with perovskite structures was assessed within the idealized model of hard spheres (Goldschmidt's rule). The possibility of formation of solid solutions along sections of the reciprocal system $K_{2} T_{e} I_{6}+R_{2} \mathbf{T e B r}_{6} \leftrightarrow \mathrm{K}_{2} \mathrm{TeBr}_{6}+\mathrm{Rb}_{2} \mathrm{TeI}_{6}$ was considered according to the quantitative criteria of Vozdvyzhensky. The $\mathrm{K}_{2} \mathrm{TeBr}_{6}-\mathrm{Rb}_{2} \mathrm{TeI}_{6}$ system was investigated by DTA and $\mathrm{X}$-ray diffraction and the phase diagram was constructed. The binary system is of the invariant eutectic type and characterized by the formation of limited solid solutions. On the basis of crystallographic data the bonds lengths in the crystal structures were compared with the covalent and ionic radii of the atoms. The results showed that the chemical bonds in the $K_{2} \operatorname{TeBr}_{6}\left(I_{6}\right)$ and $\operatorname{Rb}_{2} \operatorname{TeBr}_{6}\left(I_{6}\right)$ ternary compounds are of the mixed (combined) type - iono-covalent with a larger ionic component. The electronic structures of the $K_{2}\left(\operatorname{Rb}_{2}\right) \operatorname{TeBr}_{6}\left(I_{6}\right)$ compounds were calculated by the $a b$ initio quantum-mechanical DFT method.

Halide perovskite / Phase diagram / Crystal structure / Ab initio calculations / Electronic structure

\section{Introduction}

The obtaining of new materials with luminescent, optical and other properties is an important task of inorganic materials science. Complex halides cause sustained interest among inorganic materials that are promising for use in modern semiconductor devices, such as solar cells. Metal-organic halide perovskites have high photoelectric performance [1-3]. The power conversion efficiencies of solar cells based on perovskites reach over $20 \%$ and approach by their parameters silicon-based photovoltaics [4-8]. However, their commercial use is limited by two drawbacks: the organic cation reduces the stability of the perovskite structure, and the lead content worsens the toxicity. To increase the stability of the structure, isovalent substitution of the organic cation by an alkali metal cation $\left(\mathrm{K}^{+}, \mathrm{Rb}^{+}, \mathrm{Cs}^{+}\right.$, or one-charge $\left.\mathrm{Cu}^{+}, \mathrm{Ag}^{+}\right)$ has been proposed. To eliminate the toxicity of $\mathrm{Pb}$, the idea of its substitution by other divalent cations outside of group IVA has been considered. However, it turned out that such compounds have less good optoelectric properties for use as solar cells (too wide band gap) [9]. In this direction the most promising substitutions in the structures of these compounds are two $\mathrm{Pb}^{2+}$ ions by one $M^{+}$ion and one $M^{3+}$ ion, or one $M^{4+}\left(2 \mathrm{~Pb}^{2+} \rightarrow M^{+}+M^{3+}, 2 \mathrm{~Pb}^{2+} \rightarrow M^{4+}\right)$, maintaining the total number of valence electrons constant. As potential substitutes for $\mathrm{Pb}^{2+}$ compounds, halide double perovskites of the $A_{2} B 1 B 2 X_{6}$ type and vacancyordered double perovskites of the $A_{2} B \square X_{6}$ (where $\square$ is a vacancy) type have been proposed [10-13].

Investigation of the reciprocal $\mathrm{K}_{2} \mathrm{TeI}_{6}+\mathrm{Rb}_{2} \mathrm{TeBr}_{6}$ $\leftrightarrow \mathrm{K}_{2} \mathrm{TeBr}_{6}+\mathrm{Rb}_{2} \mathrm{TeI}_{6}$ system is a necessary stage in the study of the system with double cationcationic and anion-anionic substitution on the basis of $A_{2} B X_{6}$-type compounds.

The $\mathrm{K}(\mathrm{Rb}) \mathrm{Br}(\mathrm{I})-\mathrm{TeBr}(\mathrm{I})$ systems feature $\mathrm{K}_{2}\left(\mathrm{Rb}_{2}\right) \operatorname{TeBr}_{6}\left(\mathrm{I}_{6}\right) \quad$ compounds, which melt congruently $[14,15]$. The binary systems on the base of $A_{2} \mathrm{TeX}_{6}(A=\mathrm{K}, \mathrm{Rb}, X=\mathrm{Br}, \mathrm{I})$ compounds with cation-cationic or anion-anionic substitutions have 
been investigated [16]. The $\mathrm{K}_{2} \mathrm{TeBr}_{6}-\mathrm{Rb}_{2} \mathrm{TeBr}_{6}$ and $\mathrm{Rb}_{2} \mathrm{TeBr}_{6}-\mathrm{Rb}_{2} \mathrm{TeI}_{6}$ systems are characterized by eutectic interaction, whereas the $\mathrm{K}_{2} \mathrm{TeI}_{6}-\mathrm{Rb}_{2} \mathrm{TeI}_{6}$ system belongs to the peritectic type. In the $\mathrm{K}_{2} \mathrm{TeBr}_{6}-\mathrm{K}_{2} \mathrm{TeI}_{6}$ system at high temperatures a eutectic process takes place, and at low temperatures an unlimited solid solution is formed.

\section{Experimental details}

The ternary compounds $\mathrm{K}_{2}\left(\mathrm{Rb}_{2}\right) \mathrm{TeBr}_{6}\left(\mathrm{I}_{6}\right)$ were synthesized by reacting stoichiometric amounts of high-purity elements, tellurium, bromine, iodine with purity not less than $99.8 \mathrm{wt} \%$ and additionally purified by zone crystallization methods, binary $\operatorname{KBr}(\mathrm{I})$ and $\operatorname{RbBr}(\mathrm{I})$. The syntheses were performed by the direct two-temperature method at temperatures $50 \mathrm{~K}$ above $T_{\text {melt }}$ of the ternary compounds $\left(\mathrm{K}_{2} \mathrm{TeBr}_{6}-\right.$ $773 \mathrm{~K}, \quad \mathrm{~K}_{2} \mathrm{TeI}_{6}-733 \mathrm{~K}, \quad \mathrm{Rb}_{2} \mathrm{TeBr}_{6}-1013 \mathrm{~K}$, $\mathrm{Rb}_{2} \mathrm{TeI}_{6}-843 \mathrm{~K}$ ) in special two-section quartz ampoules. The heating was carried out at a rate of $40-60 \mathrm{~K} / \mathrm{h}$. Thermal treatment was carried out at the maximum temperature for $72 \mathrm{~h}$ (components and products of the interaction were in molten form, which led to completion of the chemical interaction with the formation of the necessary phases). Cooling was carried out at a rate of $20-30 \mathrm{~K} / \mathrm{h}$ to an annealing temperature of $473 \mathrm{~K}$ ( $96 \mathrm{~h}$ annealing), followed by cooling of the ampoule in air. Alloys of the $\mathrm{K}_{2} \mathrm{TeBr}_{6}-\mathrm{Rb}_{2} \mathrm{TeI}_{6}$ system were synthesized from the ternary compounds along the whole concentration range with a step of $10 \mathrm{~mol} . \%$.

The obtained compounds and alloys were investigated by differential thermal analysis (DTA) (combined Chromel-Alumel thermocouples, automatic data recording on a computer, heating/cooling rates of $700 \mathrm{~K} / \mathrm{h}$, measurement accuracy $\pm 5 \mathrm{~K}$ ). X-ray powder diffraction was performed using a DRON 4-07 diffractometer $\left(\mathrm{Cu} K_{\alpha}\right.$ radiation, Ni-filter, scanning interval $10 \leq 2 \theta \leq 60^{\circ}$, scanning step $0.05^{\circ}$, exposure time $5 \mathrm{~s}$ ). Crystal-chemical analysis and visualization were carried out using the program packages UnitCell (Holland-Redfern method) [17], PowderCell 2.3, Westa 3 [18], and Diamond 2. Ab initio quantummechanical calculations of the electronic structure were performed by the Quantum Espresso program (QE), which contains the core packages for the calculation of electronic-structure properties within the Density-Functional Theory (Plane-Wave basis set and pseudopotentials) $[19,20]$.

\section{Results and discussion}

The crystal structure of perovskite with the general formula $\mathrm{ABO}_{3}$ is cubic and is characterized by the presence of two types of position - cuboctahedral (coordination number $\mathrm{CN}=\mathrm{XII}$ ) and octahedral $(\mathrm{CN}=\mathrm{VI})$, occupied by atoms of the cations $A$ and $B$
(Fig. 1), respectively [21]. The $B_{6}$ octahedra, which are connected by vertices, form an infinite threedimensional framework, in the cavities of which are located $A$-cations surrounded by 12 oxygen atoms. The peculiarity of perovskites of the $\mathrm{ABO}_{3}$ type is that when part of the $A$ and $B$ cations are replaced in the corresponding sublattice, the structure as a whole remains stable (the structure is tolerant). This allows not only isovalent substitutions, but also heterovalent ones, with a violation of the electroneutrality of the system, which leads to changes in the crystal structure, the formation of defects, accompanied by orthorhombic and rhombohedral deformations. Modification of the initial structural matrix of perovskite-type phases by iso- and heterovalent substitutions should lead to the appearance of a complex of important electrical-optical properties, which promotes their practical use [22,23].
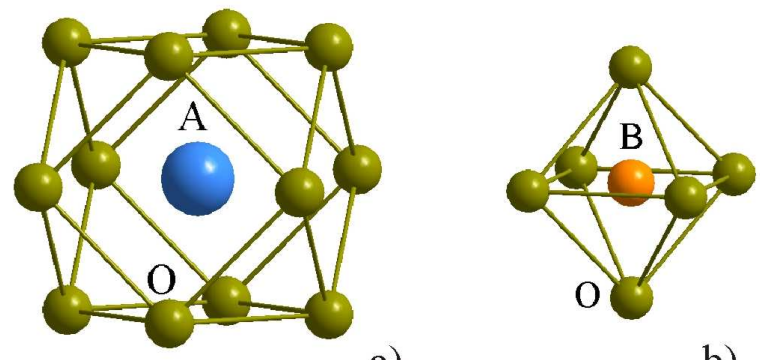

a)

b)

Fig. 1 Cuboctahedral (CN = XII) (a) and octahedral $(\mathrm{CN}=\mathrm{VI})(\mathrm{b})$ environment of $A$ and $B$ cations in the perovskite structure of the $\mathrm{ABO}_{3}$ type.

An analysis of the physical-chemical interactions in the quasi-binary systems that form the reciprocal $\mathrm{K}_{2} \mathrm{TeI}_{6}+\mathrm{Rb}_{2} \mathrm{TeBr}_{6} \leftrightarrow \mathrm{K}_{2} \mathrm{TeBr}_{6}+\mathrm{Rb}_{2} \mathrm{TeI}_{6}$ system, was performed on the basis of the electronic structures of the $\mathrm{K}(\mathrm{Rb}), \mathrm{Te}$, and $\mathrm{Br}(\mathrm{I})$ atoms, thermodynamic stability and dimensional factors. According to the electronic configuration, the $\mathrm{K}(\mathrm{Rb})$ atoms in $A_{2} \mathrm{Te} X_{6}$ ternary compounds act as cations, the $\mathrm{Br}(\mathrm{I})$ as anions, and $\mathrm{Te}$ as a central anion-forming atom.

The study of the crystallographic stability of materials in the perovskite structure within the idealized model of solid spheres is based on two empirical quantities (Goldschmidt's rule) - the tolerance factor $(t)$ and the octahedral factor $(\mu)$. A statistical analysis of perovskite halides indicates that the formation of a perovskite structure requires $0.86<t<1.0$ and $\mu>0.41$ [7]. Empirical values for the compounds $\mathrm{K}_{2}\left(\mathrm{Rb}_{2}\right) \mathrm{TeBr}_{6}\left(\mathrm{I}_{6}\right)$ were calculated according to the equations:

$$
t=\frac{R_{A}+R_{X}}{\sqrt{2} \times\left(R_{B}+R_{X}\right)} \quad(1), \quad \mu=\frac{R_{B}}{R_{X}}
$$

For $R_{A}, R_{B}, R_{X}$ we used ionic and crystalline radii according to Shannon and Pruitt (Table 1). The 
I. Barchiy et al., Reciprocal $\mathrm{K}_{2} \mathrm{TeI}_{6}+\mathrm{Rb}_{2} \mathrm{TeBr}_{6} \leftrightarrow \mathrm{K}_{2} \mathrm{TeBr}_{6}+\mathrm{Rb}_{2} \mathrm{TeI}_{6}$ system: phase relations, crystal and ...

calculations (Table 2) showed high stability of the individual ternary compounds and solid solutions based on them with the perovskite structure, especially the $\mathrm{Rb}_{2} \mathrm{TeBr}_{6}\left(\mathrm{I}_{6}\right)$ compounds.

We considered the possibility of formation of unlimited solid solutions in the binary sections of the reciprocal $\quad \mathrm{K}_{2} \mathrm{TeI}_{6}+\mathrm{Rb}_{2} \mathrm{TeBr}_{6} \leftrightarrow \mathrm{K}_{2} \mathrm{TeBr}_{6}+\mathrm{Rb}_{2} \mathrm{TeI}_{6}$ system according to the quantitative criteria of Vozdvyzhensky [26] (Table 3).

$$
n_{s} \leq 1.1 \div 1.2 \quad \text { (3), } \quad 4 n_{t}^{2}+n_{v}{ }^{2} \leq 1.0
$$

where $n_{s}$ - the entropy factor (ratio of entropies of melting $S_{A} / S_{B}$ for $\left.S_{A}>S_{B}\right) ; n_{t}-$ the temperature factor equal to $1-T_{A} / T_{B}$ (for $T_{A}<T_{B}$ ) and $1-T_{B} / T_{A}$ (for $\left.T_{A}>T_{B}\right) ; \quad n_{v}-$ volume or dimensional factor $\left[\left(d_{A} / d_{B}\right)^{3}+V_{A} / V_{B}-2\right]+b\left(d_{A}, d_{B}, V_{A}, V_{B}-\right.$ size of the ions, volumes of unit cells, $b$ - correction in valence differences).

The first criterion $\left(n_{s}\right)$ characterizes the degree of homogeneity of the chemical bonds in the compounds, the second one $\left(4 n_{t}{ }^{2}+n_{v}{ }^{2}\right)$ the proximity of their physicochemical properties. Taking this into consideration the nature of the interaction between the ternary halides was studied for the possible formation of solid solutions.

Due to the polymorphous transformation of the $\mathrm{K}_{2} \mathrm{TeI}_{6}$ compound, the $\mathrm{K}_{2} \mathrm{TeBr}_{6}-\mathrm{K}_{2} \mathrm{TeI}_{6}$ system is characterized by eutectic interaction at high temperatures, which is confirmed by the deviation of the entropy factor from the condition $n_{s}>1.1 \div 1.2$. At low temperatures an unlimited solid solution is formed (confirmed condition $4 n_{\mathrm{t}}{ }^{2}+n_{v}{ }^{2} \leq 1$ ) (Table 3). The other systems based on the $\mathrm{K}_{2}\left(\mathrm{Rb}_{2}\right) \operatorname{TeBr}_{6}\left(\mathrm{I}_{6}\right)$ ternary compounds are characterized by the formation of boundary solid solutions (IV-V types of phase diagrams according to Roozeboom) (Fig. 2).

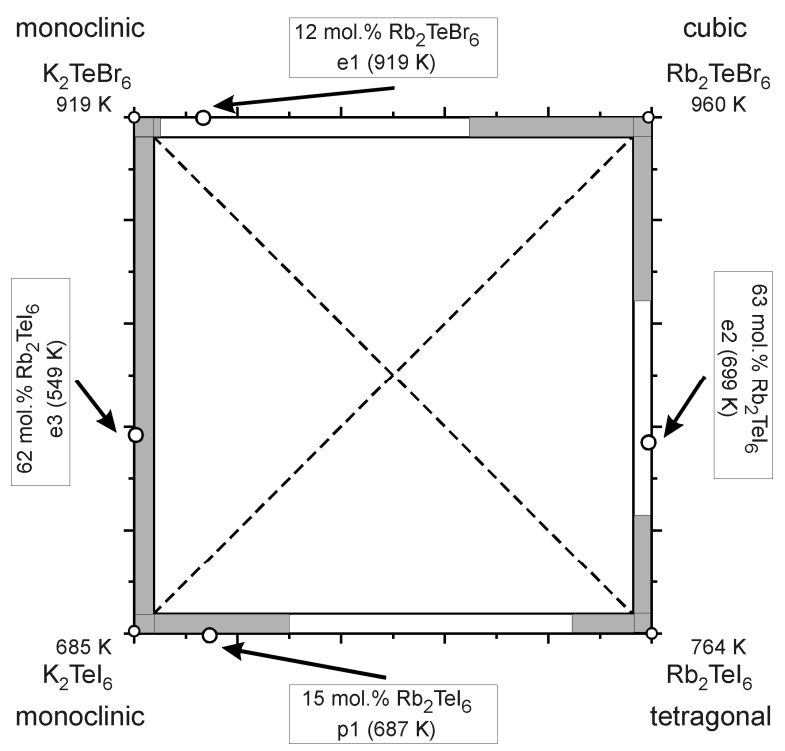

Fig. 2 Phase relations along the binary sections of the reciprocal $\mathrm{K}_{2} \mathrm{TeI}_{6}+\mathrm{Rb}_{2} \mathrm{TeBr}_{6} \leftrightarrow$ $\mathrm{K}_{2} \mathrm{TeBr}_{6}+\mathrm{Rb}_{2} \mathrm{TeI}_{6}$ system.

Table 1 Energy parameters of the elements that are part of the $\mathrm{K}_{2}\left(\mathrm{Rb}_{2}\right) \operatorname{TeBr}_{6}\left(\mathrm{I}_{6}\right)$ compounds.

\begin{tabular}{c|c|c|c|c|c}
\hline \multirow{2}{*}{ Symbol } & \multirow{2}{*}{$\begin{array}{c}\text { Electronic } \\
\text { configuration }\end{array}$} & \multicolumn{2}{|c|}{$\chi$} & $r_{\text {cov }}, \AA$ & $r_{\text {ion }}, \AA$ \\
\cline { 3 - 5 } & & {$[24]$} & {$[24]$} & {$[24]$} & {$[25]$} \\
\hline $\mathrm{K}$ & {$[\mathrm{Ar}] 4 \mathrm{~s}^{1}$} & 0.8 & 0.4 & 2.24 (octahedral) & $(+1) 1.64(\mathrm{CN}$ XII) \\
$\mathrm{Rb}$ & {$[\mathrm{Kr}] 5 \mathrm{~s}^{1}$} & 0.8 & 0.4 & 2.56 (octahedral) & $(+1) 1.72(\mathrm{CN}$ XII) \\
$\mathrm{Te}$ & {$[\mathrm{Kr}] 5 \mathrm{~s}^{2} 5 \mathrm{p}^{4}$} & 2.1 & 2.1 & 1.41 (tetrahedral) & $(+4) 0.97(\mathrm{CN}$ VI) \\
$\mathrm{Br}$ & {$[\mathrm{Ar}] 4 \mathrm{~s}^{2} 4 \mathrm{p}^{5}$} & 2.8 & 3.0 & 1.22 (tetrahedral) & $(-1) 1.96(\mathrm{CN}$ VI) \\
$\mathrm{I}$ & {$[\mathrm{Kr}] 5 \mathrm{~s}^{2} 5 \mathrm{p}^{5}$} & 2.5 & 2.8 & 1.40 (tetrahedral) & $(-1) 2.20(\mathrm{CN}$ VI) \\
\hline
\end{tabular}

Table 2 Tolerance $(t)$ and octahedral factors $(\mu)$ for $\mathrm{K}_{2}\left(\mathrm{Rb}_{2}\right) \operatorname{TeBr}_{6}\left(\mathrm{I}_{6}\right)$.

\begin{tabular}{c|c|c|c|c}
\hline Compound & $\mathrm{K}_{2} \mathrm{TeBr}_{6}$ & $\mathrm{~K}_{2} \mathrm{TeI}_{6}$ & $\mathrm{Rb}_{2} \mathrm{TeBr}_{6}$ & $\mathrm{Rb}_{2} \mathrm{TeI}_{6}$ \\
\hline$t$ & 0.8688 & 0.8566 & 0.8881 & 0.8744 \\
$\mu$ & 0.4949 & 0.4409 & 0.4949 & 0.4409 \\
\hline
\end{tabular}

Table 3 Quantitative criteria for the possibility of formation of solid solutions in the $\mathrm{K}_{2}\left(\mathrm{Rb}_{2}\right) \operatorname{TeBr}_{6}\left(\mathrm{I}_{6}\right)$ quasibinary systems.

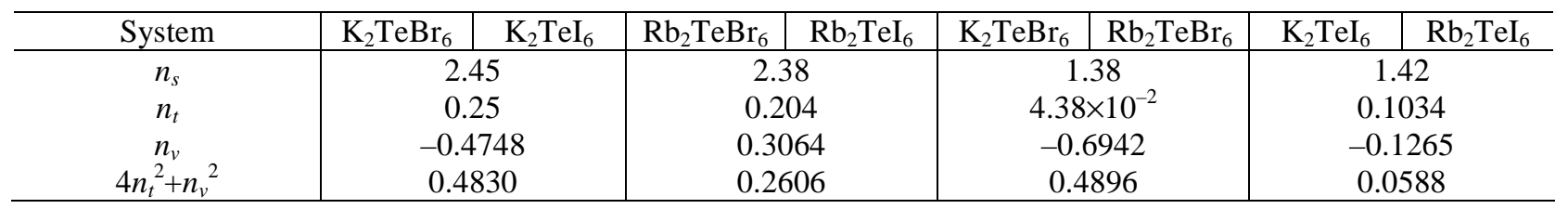


I. Barchiy et al., Reciprocal $\mathrm{K}_{2} \mathrm{TeI}_{6}+\mathrm{Rb}_{2} \mathrm{TeBr}_{6} \leftrightarrow \mathrm{K}_{2} \mathrm{TeBr}_{6}+\mathrm{Rb}_{2} \mathrm{TeI}_{6}$ system: phase relations, crystal and ...

To study the direction of the exchange reaction (determination of the quasi-binary cross-section) in the reciprocal $\mathrm{K}_{2} \mathrm{TeI}_{6}+\mathrm{Rb}_{2} \mathrm{TeBr}_{6} \leftrightarrow$ $\mathrm{K}_{2} \mathrm{TeBr}_{6}+\mathrm{Rb}_{2} \mathrm{TeI}_{6}$ system the composition of the alloy at the intersection of the two possible crosssections, was studied (Fig. 2). The diffraction pattern shows groups of reflections characteristic of monoclinic $\left(\mathrm{K}_{2} \mathrm{TeBr}_{6}\right)$ and tetragonal $\left(\mathrm{Rb}_{2} \mathrm{TeI}_{6}\right)$ phases. This fact indicates that the $\mathrm{K}_{2} \mathrm{TeBr}_{6}-\mathrm{Rb}_{2} \mathrm{TeI}_{6}$ section is quasi-binary and the direction of the exchange reaction is $\mathrm{K}_{2} \mathrm{TeI}_{6}+\mathrm{Rb}_{2} \mathrm{TeBr}_{6} \rightarrow$ $\mathrm{K}_{2} \mathrm{TeBr}_{6}+\mathrm{Rb}_{2} \mathrm{TeI}_{6}$.

Calculations of the quantitative criteria for the formation of solid solutions according to Vozdvyzhensky (equations 3,4) in the $\mathrm{K}_{2} \mathrm{TeBr}_{6}$ $\mathrm{Rb}_{2} \mathrm{TeI}_{6}$ system showed that the value of the entropy factor $n_{s}=1.7272\left(n_{s} \geq 1.1 \div 1.2\right)$ denies the possibility of formation of unlimited solid solutions, but the condition $4 n_{t}^{2}+n_{v}{ }^{2}=0.5816\left(4 n_{t}{ }^{2}+n_{v}{ }^{2} \leq 1.0\right)$ indicates the possibility of forming extended areas of solid solutions based on the $\mathrm{K}_{2}\left(\mathrm{Rb}_{2}\right) \mathrm{TeBr}_{6}\left(\mathrm{I}_{6}\right)$ ternary compounds.

The $\mathrm{K}_{2} \mathrm{TeBr}_{6}-\mathrm{Rb}_{2} \mathrm{TeI}_{6}$ system (Fig. 3) is the quasi-binary section of the reciprocal $\mathrm{K}_{2} \mathrm{TeI}_{6}+\mathrm{Rb}_{2} \mathrm{TeBr}_{6} \leftrightarrow \mathrm{K}_{2} \mathrm{TeBr}_{6}+\mathrm{Rb}_{2} \mathrm{TeI}_{6}$ system and is characterized by eutectic interaction ( $\mathrm{V}$ type of phase diagrams according to Roozeboom) with the formation of boundary solid solutions $\alpha$ on the basis of $\mathrm{K}_{2} \mathrm{TeBr}_{6}$ and $\beta$ on the basis of $\mathrm{Rb}_{2} \mathrm{TeI}_{6}$. The lines of

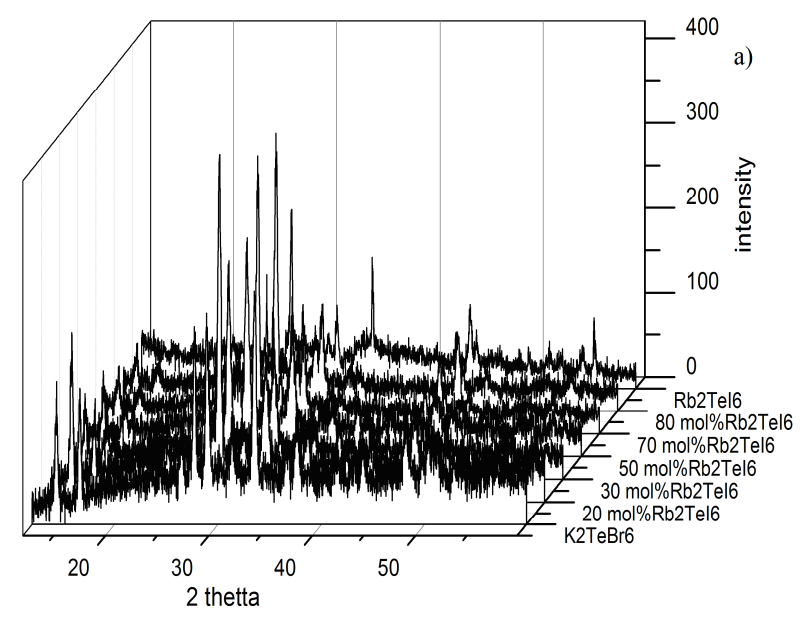

primary crystallization cross at the eutectic point ( $\mathrm{L} \leftrightarrow \alpha+\beta$ invariant process) with the coordinates 58 mol.\% $\mathrm{Rb}_{2} \mathrm{TeI}_{6}, 715 \mathrm{~K}$. The length of the solid solutions at the temperature of the invariant eutectic process are up to $35 \mathrm{~mol} . \%$ for the $\alpha$-phase and up to $25 \mathrm{~mol} . \%$ for the $\beta$-phase. At the temperature of the homogenizing annealing, $473 \mathrm{~K}$, the solid solutions extend up to $25 \mathrm{~mol} \%$ for the $\alpha$-phase and up to $15 \mathrm{~mol} . \%$ for the $\beta$-phase. The formation of boundary solid solutions is due to the crystallization of ternary compounds in different crystal structures: $\mathrm{K}_{2} \mathrm{TeBr}_{6}$ is monoclinic, whereas $\mathrm{Rb}_{2} \mathrm{TeI}_{6}$ is tetragonal (Table 4). On increasing the radius ratio from $r_{(\mathrm{Rb})} / r_{(\mathrm{I})}=0.72$ to $r_{(\mathrm{K})} / r_{(\mathrm{Br})}=0.84$ there is a transition from tetragonal to monoclinic structure (Fig. 4).

Crystal-chemical analyses showed that the $\mathrm{K}_{2}\left(\mathrm{Rb}_{2}\right) \mathrm{TeBr}_{6}\left(\mathrm{I}_{6}\right)$ compounds crystallize in the structure type $\mathrm{K}_{2} \mathrm{PtCl}_{6}$ [27-30]. The coordination octahedra $\left[\mathrm{Te} X_{6}\right]$ are formed by six halogen atoms $(X)$ surrounding the Te atom and located at the vertices of regular tetragonal bipyramids. The coordination octahedra $\left[\mathrm{Te} X_{6}\right]$ are located at the vertices and the center of a large cube; the $\mathrm{K}^{+}, \mathrm{Rb}^{+}$ions/atoms are placed between them (Fig. 4).

To establish the type of chemical bond in the $\mathrm{K}_{2} \mathrm{TeBr}_{6}\left(\mathrm{I}_{6}\right)$ and $\mathrm{Rb}_{2} \mathrm{TeBr}_{6}\left(\mathrm{I}_{6}\right)$ ternary compounds the interatomic distances were compared with the sum of the covalent and ionic radii of the atoms (Fig. 5, Table 5).

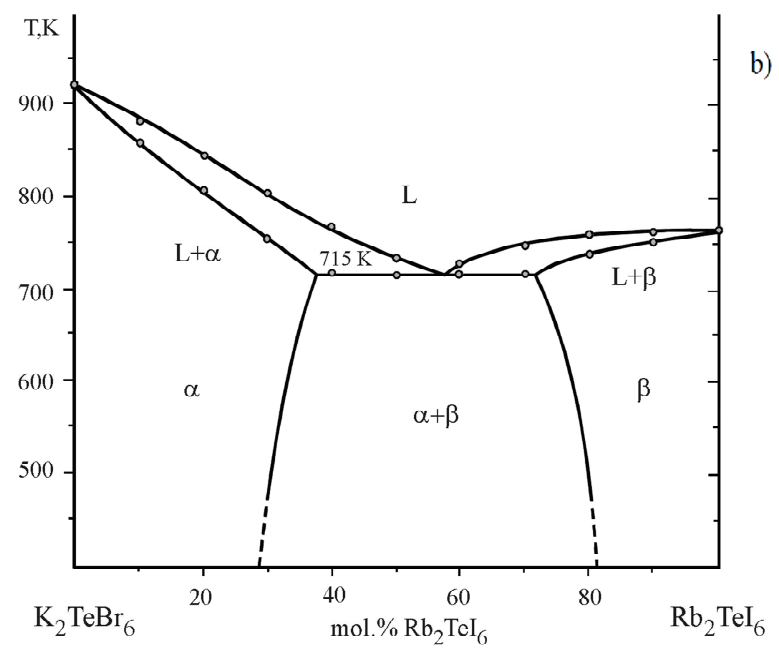

Fig. 3 X-ray powder diffraction patterns (a) and phase diagram (b) of the $\mathrm{K}_{2} \mathrm{TeBr}_{6}-\mathrm{Rb}_{2} \mathrm{TeI}_{6}$ quasi-binary system.

Table 4 Crystal-chemical parameters of the $\mathrm{K}_{2}\left(\mathrm{Rb}_{2}\right) \mathrm{TeBr}_{6}\left(\mathrm{I}_{6}\right)$ compounds.

\begin{tabular}{c|c|c|c}
\hline Compound & $\begin{array}{c}\text { Crystal } \\
\text { symmetry }\end{array}$ & Space group & Lattice parameters \\
\hline $\mathrm{K}_{2} \mathrm{TeBr}_{6}[27]$ & monoclinic & $P 12_{1} / c 1$ & $a=7.4908, b=7.5492, c=13.0272 \AA, \beta=124.79, V=604.98 \AA^{3}$ \\
$\mathrm{~K}_{2} \mathrm{TeI}_{6}[28]$ & monoclinic & $P 12_{1} / c 1$ & $a=7.9850, b=8.1710, c=13.9281 \AA, \beta=124.50, V=748.93 \AA^{3}$ \\
$\mathrm{Rb}_{2} \mathrm{TeBr}_{6}[29]$ & cubic & $F m-3 m$ & $a=10.7730, V=1250.29 \AA^{3}$ \\
$\mathrm{Rb}_{2} \mathrm{TeI}_{6}[30]$ & tetragonal & $P 4 / m n c$ & $a=8.1360, c=11.8100 \AA, V=781.76 \AA^{3}$ \\
\hline
\end{tabular}




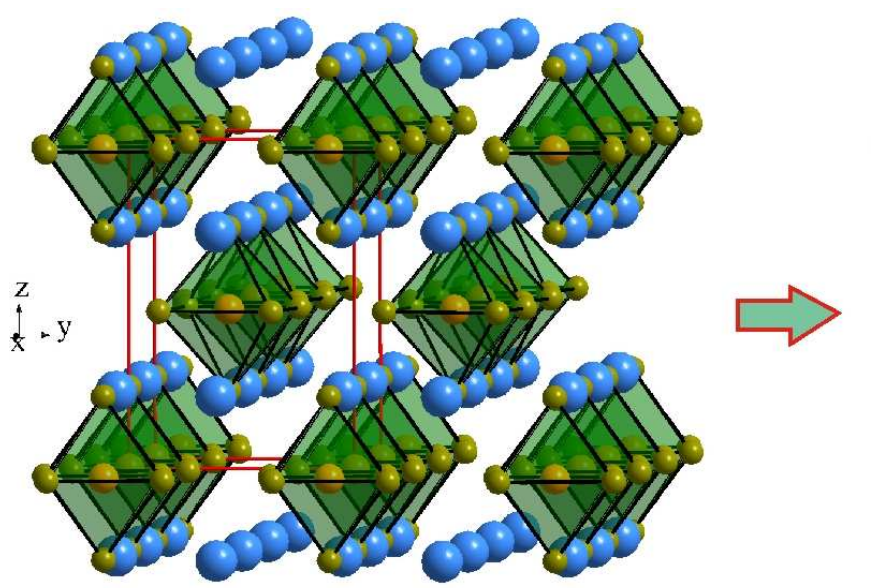

tetragonal

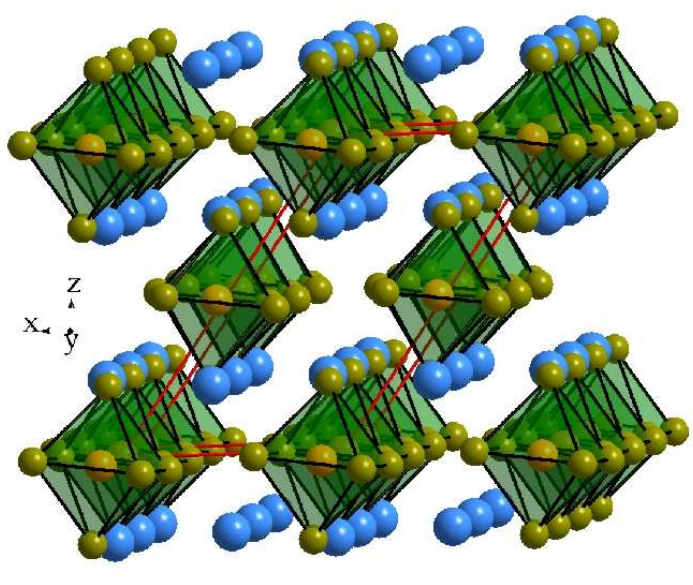

monoclinic

Fig. 4 Transition from the tetragonal structure of $\mathrm{Rb}_{2} \mathrm{TeI}_{6}$ to the monoclinic structure of $\mathrm{K}_{2} \mathrm{TeBr}_{6}$.
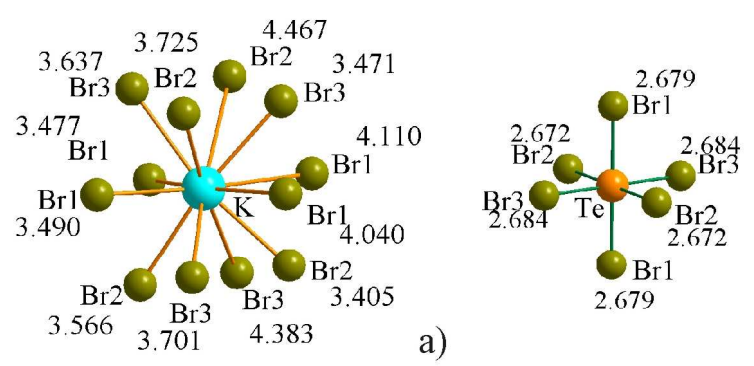

a)

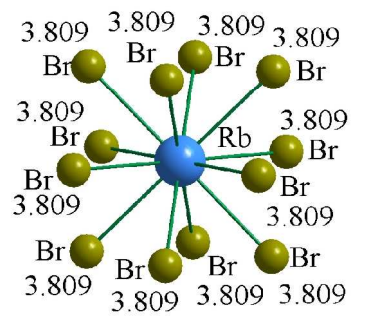

c)

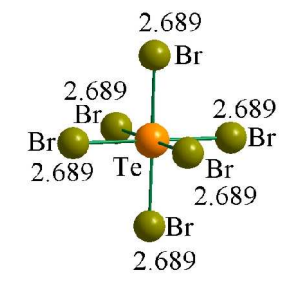

Fig. 5 Coordination environment and interatomic distances in the structures of $\mathrm{K}_{2} \mathrm{TeBr}_{6}$ (a), $\mathrm{K}_{2} \mathrm{TeI}_{6}$ (b), $\mathrm{Rb}_{2} \mathrm{TeBr}_{6}(\mathrm{c})$, and $\mathrm{Rb}_{2} \mathrm{TeI}_{6}(\mathrm{~d})$.

Table 5 Interatomic distances $(\AA)$ in the crystal structures of $K_{2}\left(\operatorname{Rb}_{2}\right) \operatorname{TeBr}_{6}\left(\mathrm{I}_{6}\right)$.

\begin{tabular}{c|c|c|c|c|c}
\hline Bonds & $\mathrm{K}_{2} \mathrm{TeBr}_{6}\left(\mathrm{I}_{6}\right)(\exp )$ & $\mathrm{Rb}_{2} \mathrm{TeBr}_{6}\left(\mathrm{I}_{6}\right)(\mathrm{exp})$ & $\sum$ cov. (calc) & $\sum$ ion. (calc) & $S_{I}{ }^{\mathrm{a}}$ \\
\hline $\mathrm{K}-\mathrm{Br}$ & $3.405-4.467$ & - & 3.46 & 3.60 & 77 \\
$\mathrm{~K}-\mathrm{I}$ & $3.574-5.173$ & - & 3.64 & 3.84 & 73 \\
$\mathrm{Rb}-\mathrm{Br}$ & - & 3.809 & 3.78 & 3.62 & 77 \\
$\mathrm{Rb}-\mathrm{I}$ & - & $3.867-4.339$ & 3.96 & 3.92 & 73 \\
$\mathrm{Te}-\mathrm{Br}$ & $2.672-2.684$ & 2.689 & 2.63 & 2.93 & 32 \\
$\mathrm{Te}-\mathrm{I}$ & $2.923-2.937$ & $2.929-2.931$ & 2.81 & 3.17 & 26 \\
$\mathrm{Br}-\mathrm{Br}$ & $3.770-3.8043$ & 3.803 & 2.44 & 3.92 & 0 \\
$\mathrm{I}-\mathrm{I}$ & $4.131-4.1733$ & $4.144-4.145$ & 2.80 & 4.40 & 0 \\
\hline
\end{tabular}

${ }^{\mathrm{a}} S_{i}$ is the degree of ionicity of the bond in the crystals. 
The analysis of the interatomic distances in the $A_{2} \mathrm{Te}_{6}$ compounds showed that the experimental distances $A-X$ are slightly longer than the calculated sum of the ionic radii of the corresponding atoms. This indicates that these bonds are clearly ionic in nature. When $\mathrm{K}$ is replaced by $\mathrm{Rb}$, an increase in the interatomic distances $A-X$ is observed, which indicates an increase in the degree of ionicity of the chemical bond. The values of the Te $-X$ interatomic distances are slightly larger than the sum of the covalent and smaller than the sum of the ionic radii of the atoms, which indicates covalent nature of the corresponding bonds. With $\mathrm{Br} \rightarrow \mathrm{I}$ substitution, due to the increase of the covalent radii, an increase of the interatomic distances $\mathrm{Te}-X$ and, at the same time, a decrease of the degree of ionicity of the chemical bonds, is observed. The values of the interatomic distances $\mathrm{Te}-X$ change insignificantly when $\mathrm{K}$ is replaced by $\mathrm{Rb}$, which underlines the stability of the complex ion $\left[\mathrm{Te} X_{6}\right]^{2-}$. The analysis of the results indicates that the chemical bonding in ternary $A_{2} \mathrm{Te} X_{6^{-}}$ type halide compounds has a mixed chemical bond type - iono-covalent with predominance of the ionic component. In fact, compounds of this type can be considered as ionic compounds, where the role of the cation is played by the element $A$, and the role of the anion by the stable complex ion $\left[\mathrm{Te} X_{6}\right]^{2-}$. In the $A_{2} \mathrm{Te} X_{6}$-type complex compounds an increase in the ionicity of the $A-X$ bond caused by the replacement of $\mathrm{K}$ by $\mathrm{Rb}$ in the outer coordination sphere leads to an increase in the degree of covalence of the bonding in the inner sphere of the complex ion $\left[\mathrm{Te} X_{6}\right]^{2-}$. Since the change in the electronegativity of the alkali metal atoms occurs symbatically with the change of their ionic radii, the obtained results are in good agreement with the compensatory dependence - the smaller the size of the outer spherical cation, the larger the overall size of the complex anion.
We considered the structure of the octahedral $\left[\mathrm{Te} X_{6}\right]^{2-}$ complex ions within the ligand field theory (LFT) and the molecular orbital (MO) method, in which only $\sigma$-bonds are present (Fig. 6). The overlap of the orbitals of the central atom and the six ligands contributes to a series of molecular orbitals.

During the formation of the $\mathrm{Te}^{4+}$ ion, the $5 p^{4}$-electrons are separated. Paired $5 s^{2}$-electrons do not come off, which is due to the $4 d$-level shielding. In an isolated $\mathrm{Te}^{4+}$ ion, the $4 d$ orbitals are completely filled with ten paired electrons and do not participate in the formation of bonds. The five $5 d$ orbitals of the external energy level are closer to the ligand ions than the $4 d$ orbitals of the penultimate level, which leads to a denser overlap of $d_{z^{2}}$ and $d_{x^{2}-y^{2}}$ orbitals with the $p$ orbitals of the halogen ions with the formation of two molecular bonding $e_{g}$ orbitals. The $d_{x z}, d_{x y}$, and $d_{y z}$ orbitals do not directly participate in the formation of bonds with halogens and form $t_{2 g}$ nonbonding MO. Free $5 p$ and $5 s$ orbitals filled with two paired electrons, in turn, form four bonding (one $a_{1 g}$ and three $t_{1 u}$ ) molecular orbitals. 12 of the 14 valence electrons ( 2 electrons of the $\mathrm{Te}^{4+}$ ion and 12 electrons of the ligands - halogen ions $X^{-}$) are located in the $a_{1 g}$, $t_{1 u}$, and $e_{g}$ bonding molecular orbitals. The other two electrons are located in $t_{2 g}$ nonbonding orbitals. The presence of unpaired electrons in $t_{2 g}$ is confirmed by the fact that in the complexes there is a distortion of the octahedral configuration (the configuration of a tetragonal bipyramid - distorted octahedron - is more stable) if the complexing agent contains in its $d$ orbitals nonbound electrons, asymmetrically with respect to the others (resulting in deformation of the structure). For the same ligand $X^{-}$, in the direction $\mathrm{Rb}^{+}$ to $\mathrm{K}^{+}$, a decrease in the symmetry of the polyatomic complex $A_{2} \mathrm{TeX}_{6}$ from tetragonal (cubic) to monoclinic is observed.

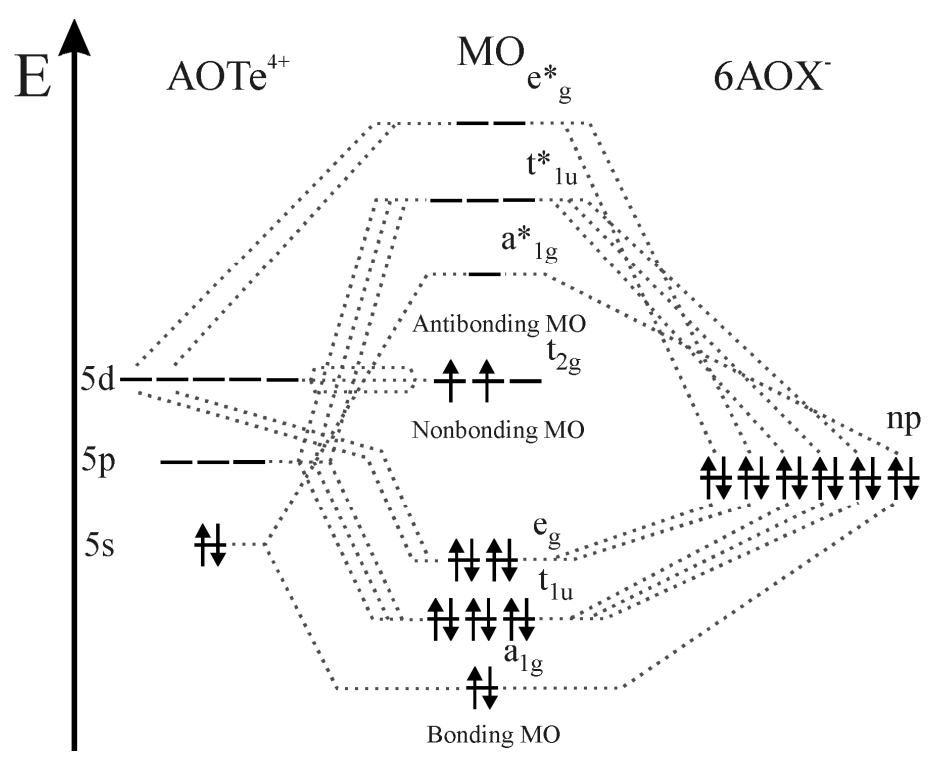

Fig. 6 Distribution of the electrons in the molecular orbitals of the complex ion $\left[\mathrm{Te} X_{6}\right]^{2-}(X=$ halogen). 
I. Barchiy et al., Reciprocal $\mathrm{K}_{2} \mathrm{TeI}_{6}+\mathrm{Rb}_{2} \mathrm{TeBr}_{6} \leftrightarrow \mathrm{K}_{2} \mathrm{TeBr}_{6}+\mathrm{Rb}_{2} \mathrm{TeI}_{6}$ system: phase relations, crystal and ...

$A b$ initio quantum-mechanical calculations of the electronic structure of the $\mathrm{K}_{2}\left(\mathrm{Rb}_{2}\right) \mathrm{TeBr}_{6}\left(\mathrm{I}_{6}\right)$ compounds were performed by the density functional theory (DFT) method (Quantum Espresso package). The structure geometry was optimized using the selfconsistent field method (SCF) based on the BrudenFletcher-Goldfarb-Shanno (BFGS) algorithm. The band structure calculations for the $\mathrm{K}_{2}\left(\mathrm{Rb}_{2}\right) \mathrm{TeBr}_{6}\left(\mathrm{I}_{6}\right)$ compounds were performed along the lines that connect the high-symmetry points of the first Brillouin zone (BZ) (Fig. 7). Based on the theoretical bandstructure calculations, the total density of states (DOS) of the energy distribution of the electronic states within the valence-band and conduction area were determined (Fig. 8). Results of the DFT calculations (semiconductor type, unit-cell energy, energy per atom, Fermi energy, band gap) are presented in Table 6.
In order to characterize the origin of the energy levels, the total and different partial densities of states were calculated. As one can see from Fig. 8, the top of the valence band is formed by $4 p$ electrons of bromine (or $5 p$ of iodine), while the bottom of the conduction band is formed by $5 d$ states of $\mathrm{Te}$ and $5 s$ states of $\mathrm{Br}$ (or $6 s$ states of I). The optical band gap can be created by $\operatorname{Br}(\mathrm{I}) \quad 4 p(5 p) \rightarrow \operatorname{Br}(\mathrm{I}) \quad 5 s(6 s)$ or by Te $5 d$ electrons. The potassium $4 s$ states are located at $-10.8 \mathrm{eV}, 3 p$ at -13.8 and $-12.3 \mathrm{eV}$, rubidium $5 s$ at $-10.6 \mathrm{eV}, 4 p$ at $-26.4 \mathrm{eV}$. The levels of the tellurium atom are $-10.8 \mathrm{eV}(4 s)$, $-3.9 \div-4.5 \mathrm{eV}(4 p)$ and $-12.4 \div-13.6 \mathrm{eV}(3 d)$. The levels of the halogen atoms are $\mathrm{Br} 4 s(-15.0$ and $-13.8 \mathrm{eV})$, Br $4 p$ (series of peaks $-2.9 \div-1.9 \mathrm{eV}$ ), I $5 s(-15.6$, -12.1 and $-10.8 \mathrm{eV}$ ), I $5 p$ (series of peaks $-2.9 \div-1.5 \mathrm{eV})$.

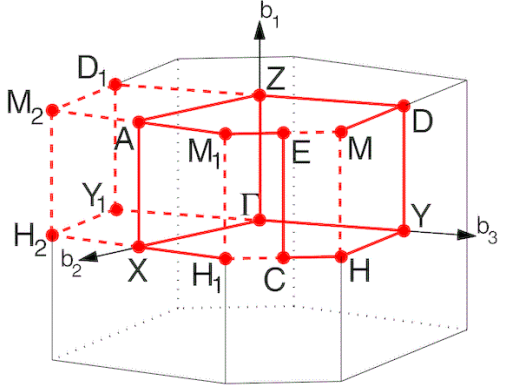

a)

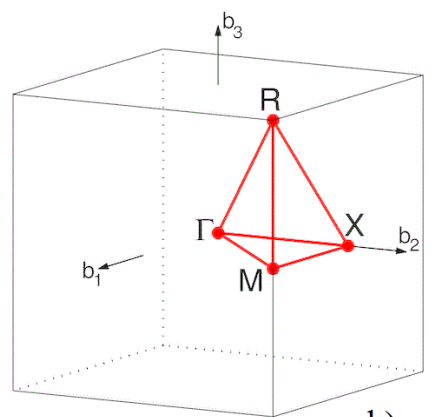

b)

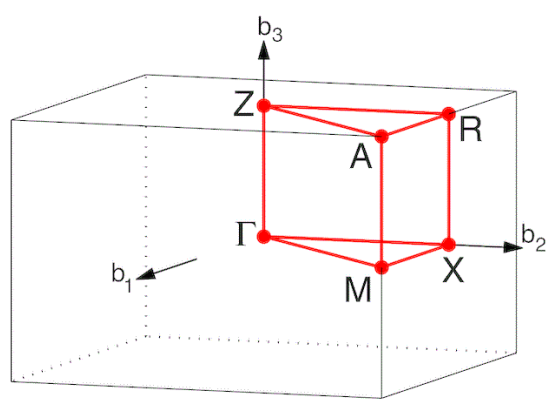

c)

Fig. 7 First Brillouin zone of the primitive monoclinic (a), primitive tetragonal (b), and primitive cubic (c) lattices [31].
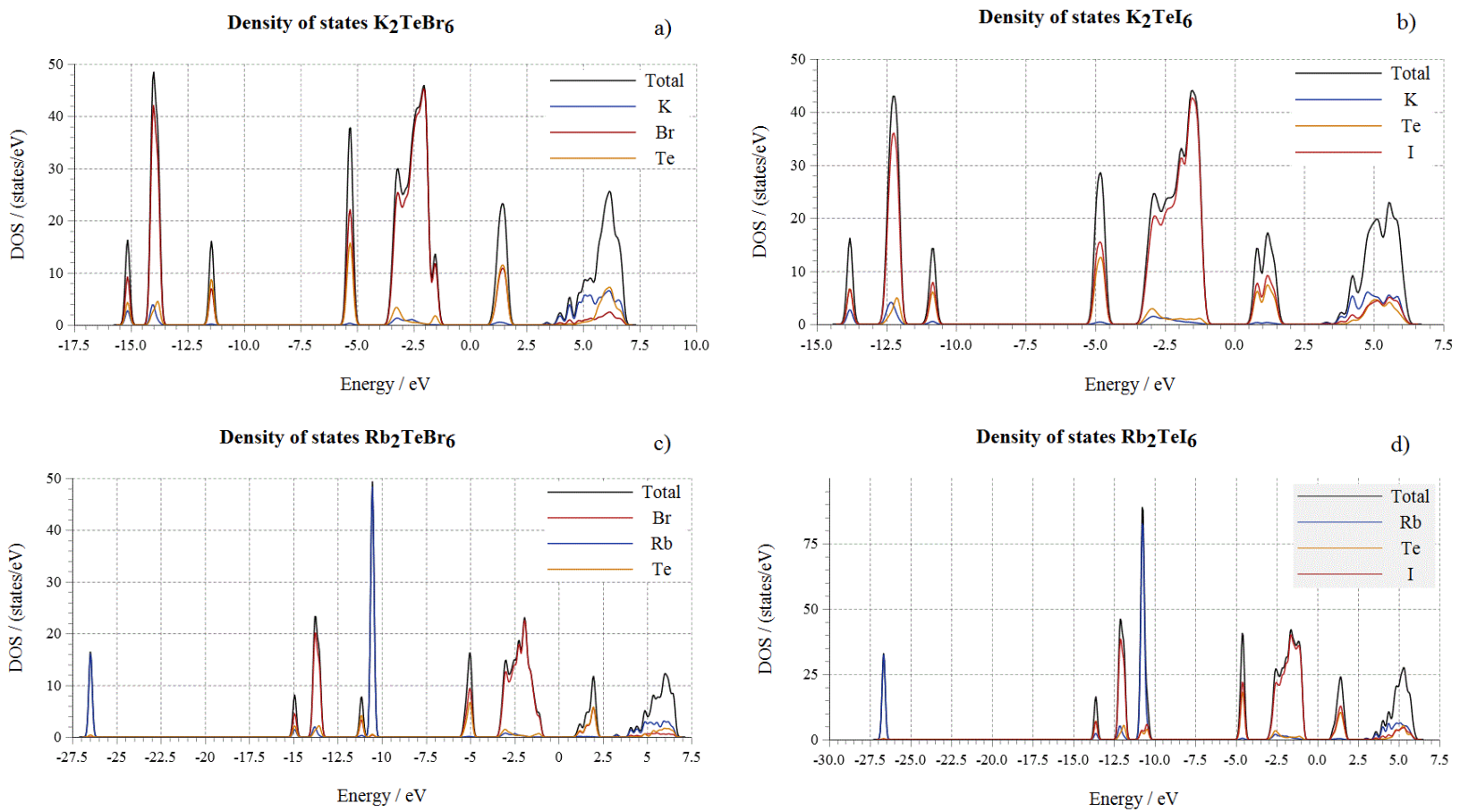

Fig. 8 Total and partial DOS of $\mathrm{K}_{2} \mathrm{TeBr}_{6}(\mathrm{a}), \mathrm{K}_{2} \mathrm{TeI}_{6}(\mathrm{~b}), \mathrm{Rb}_{2} \mathrm{TeBr}_{6}$ (c), and $\mathrm{Rb}_{2} \mathrm{TeI}_{6}$ (d). 
I. Barchiy et al., Reciprocal $\mathrm{K}_{2} \mathrm{TeI}_{6}+\mathrm{Rb}_{2} \mathrm{TeBr}_{6} \leftrightarrow \mathrm{K}_{2} \mathrm{TeBr}_{6}+\mathrm{Rb}_{2} \mathrm{TeI}_{6}$ system: phase relations, crystal and ...

Table 6 Characteristic parameters of the electronic structures of $K_{2}\left(\operatorname{Rb}_{2}\right) \operatorname{TeBr} 6\left(I_{6}\right)$.

\begin{tabular}{c|c|c|c|c|c|c|c}
\hline Compound & $\begin{array}{c}\text { Semiconductor } \\
\text { type }\end{array}$ & $E_{u c}, \mathrm{eV}$ & $E /$ atom, eV & $E_{\text {Fermi }}, \mathrm{eV}$ & $V B_{\text {max }}, \mathrm{eV}$ & $C B_{\min }, \mathrm{eV}$ & $E_{\mathrm{g}}, \mathrm{eV}$ \\
\hline $\mathrm{K}_{2} \mathrm{TeBr}_{6}$ & indirect & -26.28 & -2.92 & 2.61 & -1.42 & 0.91 & 2.39 \\
$\mathrm{~K}_{2} \mathrm{TeI}_{6}$ & indirect & -22.97 & -2.55 & 2.81 & -1.06 & 0.68 & 1.74 \\
$\mathrm{Rb}_{2} \mathrm{TeBr}_{6}$ & indirect & -21.72 & -2.41 & 2.93 & -1.02 & 1.05 & 2.07 \\
$\mathrm{Rb}_{2} \mathrm{TeI}_{6}$ & indirect & -40.14 & -4.46 & 2.91 & -0.81 & 0.91 & 1.72 \\
\hline
\end{tabular}
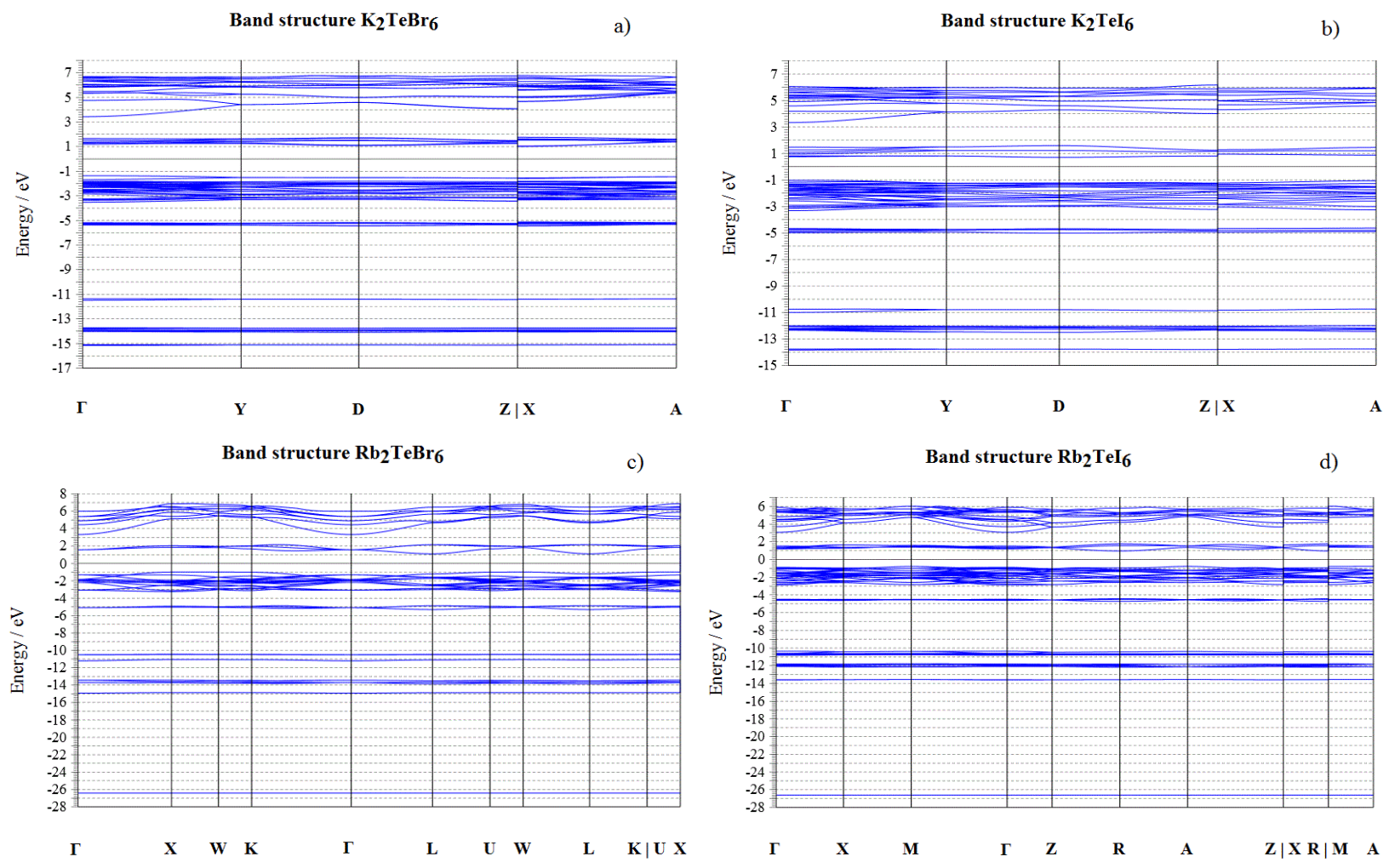

Fig. 9 Band structures of $\mathrm{K}_{2} \mathrm{TeBr}_{6}(\mathrm{a}), \mathrm{K}_{2} \mathrm{TeI}_{6}(\mathrm{~b}), \mathrm{Rb}_{2} \mathrm{TeBr}_{6}$ (c), and $\mathrm{Rb}_{2} \mathrm{TeI}_{6}(\mathrm{~d})$.

Fig. 9 shows that the calculated band gaps are equal to $E_{\mathrm{g}}=2.39 \mathrm{eV} \quad\left(\mathrm{K}_{2} \mathrm{TeBr}_{6}\right), \quad E_{\mathrm{g}}=1.74 \mathrm{eV}$ $\left(\mathrm{K}_{2} \mathrm{TeI}_{6}\right), E_{\mathrm{g}}=2.07 \mathrm{eV}\left(\mathrm{Rb}_{2} \mathrm{TeBr}_{6}\right)$, and $E_{\mathrm{g}}=1.72 \mathrm{eV}$ $\left(\mathrm{Rb}_{2} \mathrm{TeI}_{6}\right)$. At the substitutions $\mathrm{K} \rightarrow \mathrm{Rb}$ and $\mathrm{Br} \rightarrow \mathrm{I}$ the width of the forbidden zone naturally decreases, which is explained by an increase of the metal component of the chemical bond. The values of the Fermi energy $\left(E_{\mathrm{Fermi}}\right)$ for the $\mathrm{Rb}$-containing compounds are also higher than those of the K-containing compounds. The valence band maximum $\left(V B_{\max }\right)$ and conduction band minimum $\left(C B_{\min }\right)$ are located in different points of the $B Z$. This indicates that the calculated band gaps are of indirect type for all the $\mathrm{K}_{2}\left(\mathrm{Rb}_{2}\right) \operatorname{TeBr}_{6}\left(\mathrm{I}_{6}\right)$ compounds.

\section{Conclusions}

The calculation of empirical quantities (tolerance factor $t$ and octahedral factor $\mu$ according to Goldschmidt's rule) indicate high stability of the individual $\mathrm{K}_{2}\left(\mathrm{Rb}_{2}\right) \mathrm{TeBr}_{6}\left(\mathrm{I}_{6}\right)$ compounds. The possibility of extended solid solutions based on the perovskite structures in the reciprocal system $\mathrm{K}_{2} \mathrm{TeI}_{6}+\mathrm{Rb}_{2} \mathrm{TeBr}_{6} \leftrightarrow \mathrm{K}_{2} \mathrm{TeBr}_{6}+\mathrm{Rb}_{2} \mathrm{TeI}_{6}$ was confirmed using the quantitative criteria of Vozdvyzhensky. Differential thermal analysis and $\mathrm{X}$-ray diffraction were used to construct for the first time the phase diagram of the $\mathrm{K}_{2} \mathrm{TeBr}_{6}-\mathrm{Rb}_{2} \mathrm{TeI}_{6}$ system. The character of the monovariant processes, the temperature and coordinates of the invariant eutectic process $\left(58 \mathrm{~mol} \% \mathrm{Rb}_{2} \mathrm{TeI}_{6}, 715 \mathrm{~K}\right)$ in the quasi-binary system were determined. The existence of solid solutions of the $\mathrm{K}_{2} \mathrm{TeBr}_{6}$ and $\mathrm{Rb}_{2} \mathrm{TeI}_{6}$ ternary compounds was established. The crystal structures of the ternary compounds, changes in the type of chemical bond by cation-cationic $(\mathrm{K} \rightarrow \mathrm{Rb})$ and anionanionic $(\mathrm{Br} \rightarrow \mathrm{I})$ substitutions were analyzed. Ab initio quantum-mechanical calculations of the electronic structure by the DFT method showed that the $\mathrm{K}_{2}\left(\mathrm{Rb}_{2}\right) \mathrm{TeBr}_{6}\left(\mathrm{I}_{6}\right)$ compounds belong to the class of indirect-type semiconductors with band gaps of $E_{\mathrm{g}}=2.39 \mathrm{eV} \quad\left(\mathrm{K}_{2} \mathrm{TeBr}_{6}\right), \quad E_{\mathrm{g}}=1.74 \mathrm{eV} \quad\left(\mathrm{K}_{2} \mathrm{TeI}_{6}\right)$, 
$E_{\mathrm{g}}=2.07 \mathrm{eV}\left(\mathrm{Rb}_{2} \mathrm{TeBr}_{6}\right)$, and $E_{\mathrm{g}}=1.72 \mathrm{eV}\left(\mathrm{Rb}_{2} \mathrm{TeI}_{6}\right)$. The solid solutions that form in the reciprocal $\mathrm{K}_{2} \mathrm{TeI}_{6}+\mathrm{Rb}_{2} \mathrm{TeBr}_{6} \leftrightarrow \mathrm{K}_{2} \mathrm{TeBr}_{6}+\mathrm{Rb}_{2} \mathrm{TeI}_{6} \quad$ system, may serve as new semiconductor materials with a complex of appropriate physical and optical properties.

\section{References}

[1] N.J. Jeon, J.H. Noh, W.S. Yang, Y.C. Kim, S. Ryu, J. Seo, S.I. Seok, Nature 517(7535) (2015) 476-480. https://doi.org/10.1038/nature14133

[2] D.P. McMeekin, G. Sadoughi, W. Rehman, G.E. Eperon, M. Saliba, M.T. Hörantner, A. Haghighirad, N. Sakai, L. Korte, B. Rech, M.B. Johnston, L.M. Herz, H.J Snaith, Science 351(6269) (2016) 151-155.

https://doi.org/10.1126/science.aad5845

[3] D. Bi, B. Xu, P. Gao, L. Sun, M. Grätzel, A. Hagfeldt, Nano Energy 23 (2016) 138-144. https://doi.org/10.1038/srep42564

[4] G. Niu, X. Guo, L. Wang, J. Mater. Chem. A 3(17) (2015) 8970-8980. https://doi.org/10.1039/C4TA04994B

[5] M.R. Filip, F. Giustino, J. Phys. Chem. C 120(1) (2016) 166-173. https://doi.org/10.1021/acs.jpcc.5b11845

[6] S. Körbel, M.A. Marques, S.Botti, J. Mater. Chem. C 4(15) (2016) 3157-3167. https://doi.org/10.1039/C5TC04172D

[7] T.J. Jacobsson, M. Pazoki, A. Hagfeldt, T. Edvinsson, J. Phys. Chem. C 119(46) (2015) 25673-25683.

https://doi.org/10.1021/acs.jpcc.5b06436

[8] E. Mosconi, A. Amat, Md. K. Nazeeruddin, M. Gratzel, F. De Angelis, J. Phys. Chem. C 117(27) (2013) 13902-13913. https://doi.org/10.1021/jp4048659

[9] S.F. Hoefler, G. Trimmel, T. Rath, Monatsh. Chem. 148 (2017) 795-826. https://doi.org/10.1007/s00706-017-1933-9

[10] A.E. Maughan, A.M. Ganose, M.M. Bordelon, E.M. Miller, D.O. Scanlon, J.R. Neilson, J. Am. Chem. Soc. 138 (2016) 8453-8464. https://doi.org/10.1021/jacs.6b03207

[11] G. Volonakis, A.A. Haghighirad, R.L. Milot, W.H. Sio, M.R. Filip, B. Wenger, M.B. Johnston, L.M. Herz, H.J. Snaith, F. Giustino, J. Phys. Chem. Lett. 8 (2017) 772-778. https://doi.org/10.1021/acs.jpclett.6b02682

[12] Xin-Gang Zhao, Ji-Hui Yang, Fu Yuhao, Yang Dongwen, $\mathrm{Xu}$ Qiaoling, $\mathrm{Yu}$ Liping,
Wei Su-Huai, Lijun Zhang, J. Am. Chem. Soc. 139 (2017) 2630-2638. https://doi.org/10.1021/jacs.6b09645

[13] M.R. Linaburg, E.T. McClure, J.D. Majher, P.M. Woodward, Chem. Mater. 29(8) (2017) 3507-3514. https://doi.org/10.1021/acs.chemmater.6b05372

[14] E. Peresh, V. Sidey, O. Zubaka, Neorg. Mater. 41(3) (2002) 357-362 (in Russian).

[15]. E. Peresh, O. Zubaka, V. Sidey, I. Barchii, S. Kun, A. Kun, Neorg. Mater. 38(8) (2002) 1020-1024 (in Russian).

[16] I. Barchiy, Nauk. Visn. Uzhhorod. Univ., Ser. Khim. 10 (2003) 3-8 (in Ukrainian).

[17] T.J.B. Holland, S.A.T. Redfern, Mineral. Mag. 61 (1997) 65-77. https://doi.org/10.1180/minmag.1997.061.404.07

[18] W.J. Kraus, J. Appl. Crystallogr. 29(3) (1996) 301-303. https://doi.org/10.1107/S0021889895014920

[19] P. Giannozzi, O. Andreussi, T. Brumme, et al., J. Phys.: Condens. Matter 29(46) (2017) 465901. https://doi.org/10.1088/1361-648X/aa8f79

[20] A. Dal Corso, In: C. Pisani (Ed.), QuantumMechanical Ab-initio Calculation of the Properties of Crystalline Materials, LNC, Vol. 67, Springer, Berlin, Heidelberg, 1996, pp. $155-178$. https://doi.org/10.1007/978-3-642-61478-1_10

[21] R. Liu, Y. Xuan, Y.Q.Jia, Mater. Chem. Phys. 57 (1998) 81-85.

[22] N. Hara, F. Munakata, Y. Iwasaki, J. Electrochem. Soc. 145(1) (1998) 99-106.

[23] C.A. Randall, A.S. Bhalla, T.R. Shrout, J. Mater. Res. 5 (1990), 829-834. https://doi.org/10.1557/JMR.1990.0829

[24] S. Batzanov, Experimental Fundamentals of Structural Chemistry, Moscow, 1986, 240 p. (in Russian).

[25] R.D. Shannon, Acta Crystallogr. A 32 (1976) 751-767.

[26] I. Barchiy, E. Peresh, V. Rizak, V. Hudoliy, Heterogeneous Systems. Uzhhorod, 2003, 212 p. (in Ukrainian).

[27] S.C. Abrahams, J. Ihringer, P. Marsh, Acta Crystallogr. B 45 (1989) 26-34.

[28] S. Syoyama, K. Osaki, S.Kusanagi, Inorg. Nucl. Chem. Lett. 8 (1972) 181-184.

[29] W. Abriel, J. Ihringer, J. Solid State Chem. 52 (1984) 274-280.

[30] W. Abriel, Mater. Res. Bull. 17 (1982) 1341-1346.

[31] W. Setyawan, S. Curtarolo, Comput. Mater. Sci. 49 (2010) 299-312 https://doi.org/10.1016/j.commatsci.2010.05.010 